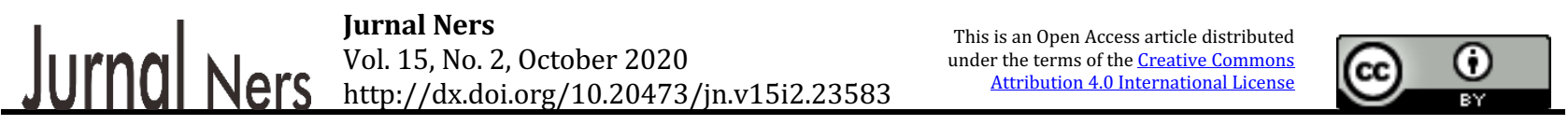

EDITORIAL

\title{
Research Utilization and Evidence-Based Practice in Education and Nursing Practice
}

\author{
Yulis Setiya Dewi ${ }^{*}$ and Smriti Kana Mani $^{2}$ \\ ${ }^{1}$ Faculty of Nursing Universitas Airlangga, Indonesia \\ 2 West Bengal University of Health Sciences, India

\section{*Corresponding Author:} \\ Dr. Yulis Setiya Dewi, S. Kep., Ns., M. Ng. \\ Faculty of Nursing Universitas Airlangga, Indonesia \\ Email: yulis.sd@fkp.unair.ac.id
}

It is widely recognized that nursing is a science and art that have changed and improved over time. The nursing profession remains core to some interdisciplinary and discipline-specific practices that may need reformation and adjustment to achieve excellent services. Space is needed to recognize and explore knowledge that comes from nursing areas and reflect on it, also finding new approaches to discuss concepts that are not easily accommodated in many different disciplines. In this editorial, we will discuss ways of improvement, namely research utilization and evidence-based practice in nursing. Let us move swiftly to make these new ideas and skills commonplace.

Research utilization is a part of evidence-based practice (EBP), which refers to applying research results as the basis to make decisions, conduct new procedures, and new policies. Most clinical decisions are based on up to date clinical knowledge and information. In addition, integrating evidence-based practice while teaching research to nursing students can help improve research knowledge, especially among those who have recently been exposed to nursing research. For nursing students, it is a good opportunity to learn about EBP incorporated into the nursing educational curriculum, combining teaching, research appraisal, application and evaluation in practice. Research utilization is about translating a new empirical finding from research into practice. Research utilization emphasizes in its translating empirically-derived knowledge into actual clinical and education application. Evidencebased practice is broader than research utilization because it assimilates research results and other fields of science. Barriers to research utilization may include rural isolation, lack of qualified nursing research, very specific findings, lack of nursing research consultants and difficulty to find good publications.

In nursing practice, education and science, evidence-based practice has been implemented widely. EBP refers to integration to recognize, assess and use research findings, patients' values, expert opinions, guidelines for practice and many other scientific relevant information and then judicially apply these in clinical practice. What skills are needed for EBP? There should be critical thinking to support ideas, inferences and beliefs. Secondly, critical appraisal skills for available evidence, which is important to determine qualified evidence. Thirdly, communication skills, which are always needed to convince about the scientific ideas and findings. Fourthly, information and technology literacy, as both are important nowadays to reach worth, valuable data and other information.

Finally, the quality for improvement and nursing transformation may waive the evidence that is effective, safe, and efficient. Developing recommendations for valuable contribution can be maximized to launch the initiatives of improvement where nurses can take the opportunity to do so. The improvement may include redesigning curriculum, developing of a structural model and implementation model, espousing practice and engaging in science for research. Therefore, research utilization and EBP become the federal ingenuities and considered opportunities to enhance existing healthcare with the new blood of improvement. 